\title{
Predictors of Residual Cardiovascular Risk in Patients on Statin Therapy for Primary Prevention
}

\author{
Luis Afonso $^{\mathrm{a}}$ Vikas Veeranna $^{\mathrm{a}}$ Sandip Zalawadiya $^{\mathrm{a}}$ Krithi Ramesh $^{\mathrm{b}}$ \\ Ashutosh Niraj ${ }^{a}$ Sidakpal Panaich ${ }^{c}$ \\ Divisions of a Cardiology and ${ }^{b}$ Endocrinology, and ${ }^{c}$ Department of Internal Medicine, Wayne State University, \\ Detroit Medical Center, Detroit, Mich., USA
}

\section{Key Words}

Statin - Primary prevention - Residual risk · Coronary artery calcium $\cdot$ Homocysteine $\cdot$ Waist circumference $\cdot$ Large artery elasticity index

\begin{abstract}
Background: Low-density lipoprotein cholesterol-lowering therapy is an important aspect of primary prevention of cardiovascular disease (CVD). Statins are the most widely used drug therapy for achieving low-density lipoprotein goals based on an individual's 10-year risk. However, substantial risk of CVD events still exists even when a person is on statins. We sought to explore the predictors of future CVD events in individuals on statins with no pre-existing CVD. Methods: The analysis was done on subjects who were on statins ( $\mathrm{n}=$ 919) at baseline in the Multi-Ethnic Study of Atherosclerosis limited access dataset from the National Heart, Lung and Blood Institute. The primary outcome variable was all-cause CVD events $(n=67)$. Multivariate regression Cox proportional hazard analysis was done to identify potential independent predictors of all-cause CVD. Results: Our cohort consisted of $47 \%$ males, with a mean age of $66 \pm 9$ years. Sixtyseven participants (7.3\%) experienced CVD events during a mean follow-up of 4.4 years. A higher coronary artery calcium score, homocysteine levels, waist circumference and a
\end{abstract}

lower large arterial elasticity index were identified as independent predictors of CVD events. Conclusion: Homocysteine, waist circumference, coronary artery calcification and the large artery elasticity index appear to be the major independent predictors of CVD events in individuals on statins with no pre-existing CVD. In addition to emphasizing weight loss, alternative approaches beyond lipid reduction may need to be explored to better characterize and attenuate the residual risk in subjects on statin therapy for primary prevention.

Copyright $\odot 2011$ S. Karger AG, Basel

\section{Background}

Statin therapy has been widely used to achieve lowdensity lipoprotein cholesterol targets as part of primary prevention of cardiovascular disease (CVD) [1]. This approach is based on the current National Cholesterol Education Program Adult Treatment Panel III (ATP III) guidelines, which advocate the determination of an indi-

Part of the data was presented as an abstract at the Annual Scientific Sessions of the American Heart Association, 15 November 2010, Chicago, III., USA

\section{KARGER}

(c) 2011 S. Karger AG, Basel

Fax +41613061234

E-Mail karger@karger.ch

www.karger.com
Accessible online at:

www.karger.com/crd
Assoc. Prof. Luis Afonso, MD

Internal Medicine

Division of Cardiology, Wayne State University

Detroit, MI 48201 (USA)

Tel. +1 313745 2620, E-Mail lafonso@ @ed.wayne.edu 
vidual's risk status [1]. Despite aggressive lipid lowering with statins and life style modifications, a significant proportion of patients still experience incident cardiovascular events, suggesting that additional operant factors could be mediating this residual risk [2]. Therefore, we sought to characterize the predictors of residual cardiovascular risk in a prospective observational cohort of individuals on statin therapy as a primary prevention measure.

\section{Methods and Data Analysis}

The Multi-Ethnic Study of Atherosclerosis (MESA) is a population-based study $(n=6,814)$ of individuals belonging to various ethnicities, aged 45-84 years at study enrollment, without a prior history of clinical CVD [3]. We performed a post-hoc analysis of the MESA Limited Access Dataset, obtained from the National Heart, Lung and Blood Institute (NHLBI). A detailed description of the study design, methods and objectives has been published previously. In brief, MESA was designed to identify the characteristics of subclinical CVD and risk factors that predict progression to clinically overt CVD or progression of the subclinical disease [3]. All variables considered in the present analysis were obtained during the initial visit of the study. After excluding patients who were not on statins and those with missing data, we identified a total of 919 adults on statin therapy, 67 of which experienced CVD events (defined as myocardial infarction, resuscitated cardiac arrest, definite angina, probable angina if followed by revascularization, stroke, stroke death, coronary heart disease death, other atherosclerotic death and other cardiovascular death). Data on study variables were calculated using standard questionnaires and procedure protocols, the details of which have been described elsewhere [3].

Statistical analysis was performed with statistical software STATA version 10 (StataCorp, College Station, Tex., USA). Univariate and backward stepwise multivariate regression Cox proportional hazard analysis was performed to identify the independent predictors of CVD events.

\section{Results}

Our cohort consisted of $47 \%$ males, with a mean age of $66 \pm 9$ years (18\% Hispanic, $43 \%$ Caucasian, $11 \%$ Chinese and 28\% African Americans). A total of 67 participants (7.3\%) experienced CVD events during a mean follow-up of 4.4 years. Baseline characteristics are compared in table 1. Table 2 shows the multivariate predictors of CVD events among those taking statins. A higher coronary artery calcium (CAC) score, serum homocysteine (Hcy) levels, waist circumference (WC) and a lower large arterial elasticity index (LAEI) were identified as independent predictors of CVD events (table 2).

\section{Discussion}

In this study attempting to assess the residual cardiovascular risk among individuals on statin therapy for primary prevention, we found CAC, serum Hcy, WC and lower LAEI to independently predict future CVD events.

As evident from our analysis, none of the traditional risk factors retained significance as independent predictors of adverse outcomes in patients on statins for primary prevention. It is especially interesting that the lipid parameters were not statistically different among the two groups, possibly indicating that the effects of statins were similar in both the groups (table 1). Indeed, CAC, Hcy, WC and LAEI have all been proven individually in prior studies as significant independent predictors of future CVD risk $[2,4,5]$. These may prove to be more important in the context of risk assessment beyond the traditional risk factors. Our study gains support from the fact that recently released guidelines highlights the utility of measuring $\mathrm{CAC}$ in asymptomatic patients at intermediate risk for appropriate risk stratification $[6,7]$. These results are significant considering that the mere presence of $\mathrm{CAC}$, irrespective of the score, was an independent predictor of future CVD event risk in this population.

Although an increasing body of evidence suggests that Hcy reduction using vitamin supplementation is not accompanied by a reduction in the occurrence of future events, the patient populations considered in these studies had pre-existing CVD unlike the population studied in our analyses $[8,9]$. Of note, data on Hcy as a primary prevention target or its utility in reclassifying the intermediate risk population is sparse at best [10].

Elevated WC, a component of metabolic syndrome, represents a high inflammatory state [11]. However, in these patients, the existing inflammatory state may not be significantly influenced by statin therapy [12]. In agreement with these data, no statistical difference between C-reactive protein values was observed between those with and without events in our study, suggesting the independent association of WC with CVD events beyond inflammation [4]. Given the salutary effects of modest weight loss on the CVD risk profile, WC might represent a potentially modifiable risk factor, worthy of further exploration, to specifically determine whether WC-reducing interventions positively impact residual risk, in the subset of individuals on statin therapy [11]. Finally, in prior studies, LAEI in patients has been shown to improve when treated with more potent statin doses, with this effect being independent of changes in the lipid profile [5]. 
Table 1. Baseline characteristic distribution for cardiovascular events among statin users $(\mathrm{n}=919)$

\begin{tabular}{|c|c|c|c|}
\hline \multirow[t]{2}{*}{ Characteristics } & \multicolumn{2}{|l|}{ CVD events } & \multirow[t]{2}{*}{$\mathrm{p}$ value } \\
\hline & no $(\mathrm{n}=852)$ & yes $(n=67)$ & \\
\hline Age, years & $65.7 \pm 8.8$ & $67.2 \pm 8.8$ & 0.158 \\
\hline Males & 45.7 & 58.2 & $0.047^{*}$ \\
\hline \multicolumn{4}{|l|}{ Race } \\
\hline Caucasians & 42.1 & 49.2 & \\
\hline Chinese & 10.9 & 7.5 & 0.572 \\
\hline African Americans & 28.8 & 23.9 & \\
\hline Body mass index & $28.9 \pm 5.2$ & $30.1 \pm 5.5$ & 0.096 \\
\hline Waist circumference & $100.7 \pm 13.1$ & $104.8 \pm 13.4$ & $0.015^{*}$ \\
\hline Hypertension & 63.1 & 73.1 & 0.101 \\
\hline Diabetes & 21.4 & 31.3 & 0.058 \\
\hline Smoking & 48.6 & 61.2 & $0.047^{*}$ \\
\hline Coronary artery calcium score & & & $<0.001^{*}$ \\
\hline $1-99$ & 31.81 & 26.87 & \\
\hline $100-299$ & 14.44 & 19.40 & \\
\hline$\geq 300$ & 18.90 & 43.28 & \\
\hline PW - large artery elasticity index & $12.9 \pm 5.6$ & $10.7 \pm 4.7$ & $<0.001^{*}$ \\
\hline PW - small artery elasticity index & $4.2 \pm 2.7$ & $3.4 \pm 1.8$ & $0.044^{*}$ \\
\hline US - common carotid intimal-medial thickness & $0.91 \pm 0.2$ & $0.99 \pm 0.2$ & $<0.001^{*}$ \\
\hline Total cholesterol, mg/dl & $181 \pm 33$ & $184 \pm 31$ & 0.537 \\
\hline High-density lipoprotein cholesterol, mg/dl & $51 \pm 16$ & $49 \pm 12$ & 0.384 \\
\hline Low-density lipoprotein cholesterol, mg/dl & $103 \pm 28$ & $107 \pm 27$ & 0.257 \\
\hline Triglycerides, mg/dl & $137 \pm 83$ & $136 \pm 65$ & 0.912 \\
\hline Total homocysteine, $\mu \mathrm{mol} / \mathrm{l}$ & $9.4 \pm 3.1$ & $11.1 \pm 5.8$ & $0.001^{*}$ \\
\hline C-reactive protein, $\mathrm{mg} / \mathrm{l}$ & $3.1 \pm 4.7$ & $3.4 \pm 4.0$ & 0.176 \\
\hline
\end{tabular}

Data are means $\pm \mathrm{SD}$, or percentages. $\mathrm{PW}=$ Pulse wave; US $=$ ultrasound. ${ }^{*} \mathrm{p}<0.05$, statistically significant.

Traditional risk factors do not entirely explain CVD risk and a significant residual risk exists beyond the risk factor assessments using these risk factors [2]. Statin therapy as part of primary prevention is based on this risk assessment [2]. Our study shows that CAC, Hcy, WC and LAEI predict events even in individuals treated with statins; these markers may need to be considered in future risk assessment of individuals to facilitate earlier identification of high-risk groups or perhaps adopt a more intensive approach to risk factor management. Additional supporting evidence of our observations comes from now established evidence that $\mathrm{CAC}$ has been shown to significantly reclassify individuals beyond the traditional risk assessment measures [6].

This study included a cohort free of any CVD at baseline but on statin therapy as part of primary prevention, and accordingly, caution should be exercised in extrapolating our results for secondary prevention in patients with known CVD. Although the number of events was
Table 2. Multivariate risk predictors of all-cause CVD in patients on statins

\begin{tabular}{|c|c|c|c|}
\hline Significant predictors* & HR & $\mathrm{p}$ value & $95 \% \mathrm{CI}$ \\
\hline \multicolumn{4}{|c|}{ Coronary artery calcium score } \\
\hline $1-99$ & 2.44 & 0.04 & $1.02-5.86$ \\
\hline $100-299$ & 3.69 & 0.006 & $1.46-9.29$ \\
\hline$\geq 300$ & 5.56 & $<0.001$ & $2.39-12.9$ \\
\hline Serum homocysteine & 2.27 & 0.03 & $1.06-4.83$ \\
\hline $\begin{array}{l}\text { Large artery elasticity by } \\
\text { pulse-waye analysis }\end{array}$ & 042 & 0003 & \\
\hline Waist circumference & $\begin{array}{l}0.42 \\
5.77\end{array}$ & 0.04 & $\begin{array}{l}0.25-0.14 \\
1.07-31.1\end{array}$ \\
\hline
\end{tabular}

$\mathrm{HR}=$ Hazard ratio; $\mathrm{CI}=$ confidence interval.

${ }^{*} \mathrm{p}<0.05$, statistically significant. 
relatively small, the large sample size comprising a multiethnic population adds to the strength of our analysis. Another limitation could be self-reporting of all medications in the study with no description of adherence patterns. Further, no information was available on the type and dosage of statins.

Our observations provide a brief but interesting insight into the understanding of residual cardiovascular risk in statin-treated patients and reiterate the further need for prospective research in the area of CVD risk assessment.

\section{Acknowledgement}

MESA is conducted and supported by the NHLBI in collaboration with the MESA Study Investigators. This paper was prepared using a limited access dataset obtained from the NHLBI and does not necessarily reflect the opinions or views of the MESA or the NHLBI.

\section{References}

1 Third Report of the National Cholesterol Education Program (NCEP) Expert Panel on Detection, Evaluation, and Treatment of High Blood Cholesterol in Adults (Adult Treatment Panel III) final report. Circulation 2002;106:3143-3421.

- 2 Helfand M, Buckley DI, Freeman M, Fu R, Rogers K, Fleming C, Humphrey LL: Emerging risk factors for coronary heart disease: a summary of systematic reviews conducted for the US Preventive Services Task Force. Ann Intern Med 2009;151:496-507.

- 3 Grant BJ, Kudalkar DP, Muti P, McCann SE, Trevisan M, Freudenheim JL, Schunemann $\mathrm{HJ}$ : Relation between lung function and RBC distribution width in a population-based study. Chest 2003;124:494-500.

4 Yusuf S, Hawken S, Ounpuu S, Bautista L, Franzosi MG, Commerford P, Lang CC, Rumboldt Z, Onen CL, Lisheng L, Tanomsup S, Wangai P Jr, Razak F, Sharma AM, Anand SS: Obesity and the risk of myocardial infarction in 27,000 participants from 52 countries: a case-control study. Lancet 2005; 366:1640-1649.
5 Akgullu C, Ozdemir B, Yilmaz Y, Kazazoglu AR, Aydinlar A: Effect of intensive statin therapy on arterial elasticity in patients with coronary artery disease. Acta Cardiol 2008 63:467-471.

6 Polonsky TS, McClelland RL, Jorgensen NW, Bild DE, Burke GL, Guerci AD, Greenland P: Coronary artery calcium score and risk classification for coronary heart disease prediction. JAMA 2010;303:1610-1616.

-7 Greenland P, Alpert JS, Beller GA, Benjamin EJ, Budoff MJ, Fayad ZA, Foster E, Hlatsky MA, Hodgson JM, Kushner FG, Lauer MS, Shaw LJ, Smith SC, Taylor AJ, Weintraub WS, Wenger NK: 2010 ACCF/AHA guideline for assessment of cardiovascular risk in asymptomatic adults. J Am Coll Cardiol 2010;56:e50-e103.

8 Armitage JM, Bowman L, Clarke RJ, Wallendszus K, Bulbulia R, Rahimi K, Haynes R, Parish S, Sleight P, Peto R, Collins R: Effects of homocysteine-lowering with folic acid plus vitamin $B_{12}$ versus placebo on mortality and major morbidity in myocardial infarction survivors: a randomized trial. JAMA 2010;303:2486-2494.
-9 Clarke R, Halsey J, Lewington S, Lonn E, Armitage J, Manson JE, Bonaa KH, Spence JD, Nygard O, Jamison R, Gaziano JM, Guarino P, Bennett D, Mir F, Peto R, Collins R: Effects of lowering homocysteine levels with B vitamins on cardiovascular disease, cancer, and cause-specific mortality: meta-analysis of 8 randomized trials involving 37,485 individuals. Arch Intern Med 2010;170:1622-1631.

10 Helfand M, Buckley D, Fleming C, Fu R, Freeman M, Humphrey L, Rogers K, Walker M: Screening for Intermediate Risk Factors for Coronary Heart Disease: Systematic Evidence Synthesis. Evidence Synthesis No 73 AHRQ Publication No 10-05141-EF-1. Rockville, Agency for Healthcare Research and Quality, 2009.

-11 Grundy SM, Cleeman JI, Daniels SR, Donato KA, Eckel RH, Franklin BA, Gordon DJ, Krauss RM, Savage PJ, Smith SC Jr, Spertus JA, Costa F: Diagnosis and management of the metabolic syndrome: an American Heart Association/National Heart, Lung, and Blood Institute Scientific Statement. Circulation 2005;112:2735-2752.

12 Liem AH, van de Woestijne AP, Zwinderman AH, Visseren FL, Jukema JW: Determinants of CRP level in statin-treated patients. Curr Med Res Opin 2008;24:1065-1068. 